\title{
Industrial Machines as a Service: Modelling industrial machinery processes
}

\author{
Virgilio Gilart-Iglesias, Francisco Maciá-Pérez, \\ Diego Marcos-Jorquera, Francisco Jose Mora-Gimeno
}

\begin{abstract}
In this paper is proposed a service model for the industrial machinery which provides a design pattern which details, classifies and organises the services that ideally the machine should possess in order to facilitate its selfmanagement and proactive management of the business logic for which it is responsible. This pattern also establishes those services which will enable the machine to communicate and cooperate with other machines or manufacturing elements, as well as with the remaining business processes. The proposed pattern are based on Service Oriented Architecture (SOA) and Web Services extensions (WS-*) in order to ensure that the industrial machinery attains high levels of self management and especially so that it can show the rest of the organisation and from a perspective of functionality, in a normalised manner, overcoming barriers imposed by technological and physical restrictions typical of these components and which traditionally have kept them isolated from the general business model.
\end{abstract}

\section{INTRODUCTION}

$I^{\prime}$ NTERNET capacity for providing clients with a choice of the most up to date and available consumer goods and at competitive prices is currently requiring the industrial sector to progress from traditional manufacturing paradigms oriented towards mass production towards models which facilitate mass customization [1].

With these new production models the client is no longer considered as a mere external entity removed from the manufacturing process itself, but rather the client becomes a part of it as an active component determining the specific characteristics of the desired product.

In order to ensure that these manufacturing models are viable, the manufacturing processes must be fully integrated in the organisation global map. It is in this sector that many difficulties still remain, since although new technologies may help considerably in remedying discrepancies, the infrastructures used at manufacturing levels are not sufficiently prepared to take advantage of the capacity that is actually available to them [2]; this is

Manuscript received January 25, 2007. This work was supported by the Ministerio de Educación y Ciencia, Spain, under Grant TIN2006-04081.

Virgilio Gilart-Iglesias, Francisco Maciá-Pérez, Diego Marcos-Jorquera and Francisco José Mora-Gimeno are with the Department of Computer Technology, University of Alicante. Carretera San Vicente s/n. 03690 San Vicente (Alicante). Spain. Email: \{vgilart,pmacia,dmarcos, fjmora\}@dtic.ua.es particularly the case in the lower levels of the organisation where production elements are found (PLC, CNC, industrial machinery, etc.)

Despite this fact, it is nevertheless true that in other business sectors such as financial management and resource management (ERP), customer service (CRM) or on-line sales (eCommerce), mature technologies which grew up with Internet have been introduced -n-tiers architectures, both business to customer (B2C) and business to business (B2B), approaches based on middleware or service oriented architectures (SOA) - and these have overcome the traditional barriers which prevented the alignment of business strategies with the tastes and needs of clients [2] [3].

If in eBusiness models a key role is played by the vision of services according to emerging concepts such as Software as a Service (SaaS) or applications on demand, in this paper it is proposed to extend this concept to that of Industrial Machine as a Service (IMaaS). In order to achieve this firstly, the appropriate technological conditions must be created in the production elements which will enable the present physical barriers preventing them to be considered with the requisite level of abstraction. This process is one of the corner stones of the proposal and we have called it the industrial machinery normalisation process [3].

This work presents a summary of this normalisation process as a general framework of development and centred on the proposal for a service model for an industrial machine.

This model provides a design pattern which details, classifies and organises the services which each machine should possess. These services facilitate self-management and proactive management of the business logic for which the machine is responsible and enable it to communicate and cooperate with other machines or manufacturing elements as well as the remaining business processes.

The proposed patterns are based on SOA and Web Services extensions (WS-*) in order to ensure that the industrial machinery attains high levels of self management and especially so that it can show the rest of the organisation and from a perspective of functionality, in a normalised manner, overcoming barriers imposed by technological and physical constraints typical of these 
components .

Specifically the intrinsic services which a machine would possess are looked at in depth with particular emphasis and detail placed on the maintenance service.

\section{BACKGROUND}

Internet has had a considerable influence on the adoption of new strategies by present day organisations in order to keep abreast of its processes — process re-engineering[4] as well as incorporating business paradigms based on services and distributed software components and deployed on n-level architectures which assist them in implementing new business models and gaining advantages from the new model of competence created [5].

Nevertheless, due to physical and technological limitations, manufacturing processes have not reached the desired level of integration and automation, and in most cases they have to be considered as legacy systems.

The first integration proposals were centred on traditional automation models based on proprietary protocols situated at a resource level of the eBusiness model as systems external to business processes (Modbus, Profibus, AS-I, FIPIO, DeviceNET, Interbus or Ethernet industrial). These proposals were the first attempts to facilitate their integration with business components using ad-hoc adaptors [6]. In other cases, such as that proposed by Schneider [7], embedded devices are incorporated (with Ethernet connection, TCP/IP support and including an integrated web server) in concepts such as transparent factory. Other manufacturers such as $\mathrm{ABB}$, go somewhat further by raising communication to higher levels of organisation using the SOAP protocol, and incorporating intelligence, self-management and proactivity into its embedded devices [8]. Along the same lines, in [9] the use of Web Services is proposed as a normalised means of accessing functionalities of the devices so that they can be integrated with enterprise resource planning systems (ERP). In addition, within the framework of European research projects there are some important initiatives which bear out our interest in this line of research, and which have produced significant results and are progressing towards SOA and embedded devices in industrial machinery as valid technologies [10] [11].

In [12] we propose to take of advantage of these same techniques to raise the level of abstraction of the production elements to enterprise level so that the integration of resources, processes and in general business logic occurs in a natural and transparent manner within the existing business models. This work establishes the need for a process which we have called: industrial machinery normalisation process. This normalisation process is divided into three stages: the physical normalisation process in which the industrial machinery is provided with the capacity for computation and communication, the middleware normalisation process, in which the characteristics of a services and components container for an industrial machine are established, and machinery services normalisation where the service model components and their relations are defined according to the requirements and needs of industrial environments. This last phase is the focus of the present work.

Changes in future manufacturing methods tend towards distributed paradigms, with weak and autonomous coupling and imply an increase in the complexity and need for response to continuous changes with a gradual reduction of costs. In order to address these changes additional functionalities are required such as: robustness, scalability, or reconfiguration while keeping the processes simple and transparent [13] [14].

Production management in physically distributed environments implies a need to take decisions at a local level [14], and therefore it is necessary to transfer part of the control and supervision logic to industrial machinery [13]. In addition, management should be self-organised, establishing a reactive and proactive behaviour [14] in response to both disruptions and unexpected changes in the short term, in order to anticipate and prepare for critical situations, establishing machinery maintenance policies [15] [16] or process quality control [17] [18].

\section{INDUSTRIAL MACHINERY NORMALIZATION PROCESS}

The normalisation process aims to reduce the current heterogeneity in production environments characterising production elements —including industrial machineryfrom the point of view of provision of the organisation's business model. This generates a vision which enables development from technological elements -industrial machinery and ICT infrastructures - to IT services in the first instance in order to finally achieve convergence with business processes.

The normalisation process covers three stages (figure 1): physical normalisation of industrial machinery, the proposal for service middleware and the definition of a model which will provide a pattern for the services which a machine should possess in order to be offered as a facility, or to facilitate self-management and self-management of the processes it executes.

This approach will provide the model with continuity and develop business processes covering all the business sectors and facilitating integral application of industry standards oriented towards process management (ISO, EFQM).

The two initial stages (physical normalisation and normalisation of service middleware) have been studies in greater detail in previous works [12]. In this paper we present a brief summary of these in order to facilitate 


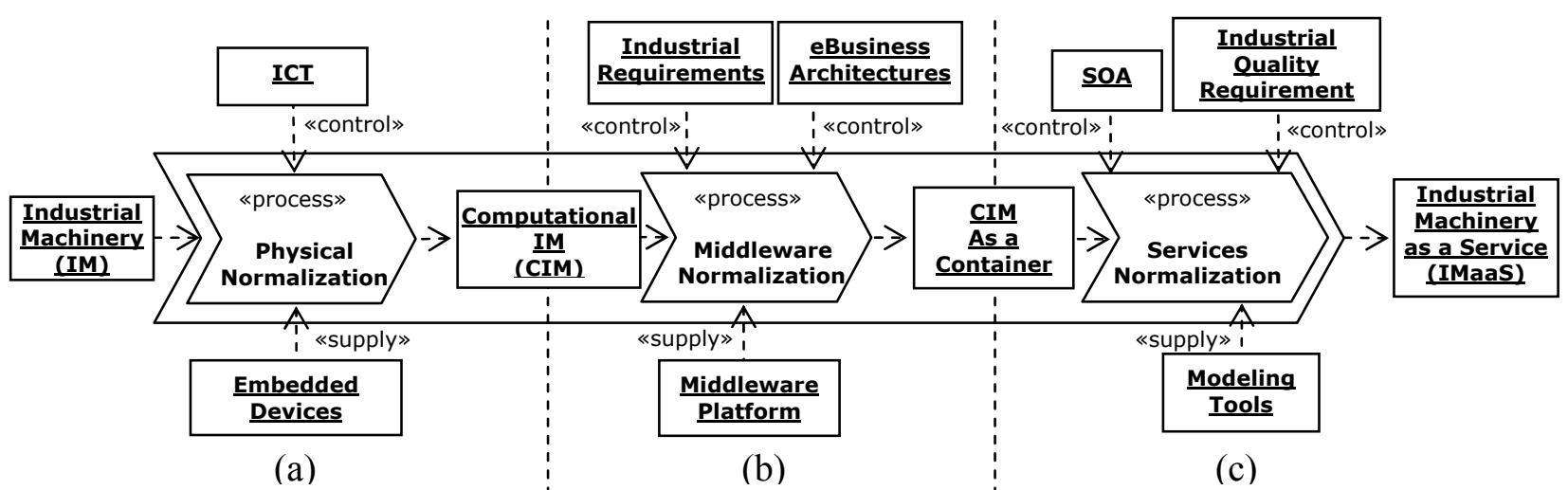

Figure 1. Industrial machinery normalization process model.

comprehension, however it is really the third stage (concerned with modelling of the manufacturing process) on which we concentrate here.

\section{A. Physical normalization}

The main purpose of this stage is to focus on providing production devices with capacity for computation and communication. With recent advances in electronics and communication a new category of small low cost computers known as embedded devices have appeared which permit integration within other systems providing them with additional characteristics. With the aid of this technology production elements can be provided with advanced functionalities, and distributed computer paradigms which have been widely disseminated with the growth of Internet can be introduced obtaining what has come to be known as intelligent devices [19] [20].

The physical normalisation process comprises the following elements (figure 1.a):

- Industrial Machinery. These are the initial basic elements which will be transformed in the process of physical normalisation. .

- Information and Communications Technologies (ICT). ICT paradigms are used in the process as transformation controller.

- Embedded Devices. These are basic instruments which provide industrial machinery with communication and computation capacities.

- Computational Industrial Machinery (CIM). This is the result obtained from the process. Industrial machinery with the capacity for computation and communication (figure 2.a).

\section{B. Middleware normalization}

The second stage defines the embedded service and component container which provides the appropriate infrastructure, in terms of middleware services, to the components which will encapsulate the functionality of the device, (figure 2.b).

In this way, the functionality of industrial machine will be determined by the software and not by the hardware thus permitting greater flexibility, autonomy and interoperability of the production components [19].

The production components are now defined as service containers conceptually similar to those currently in existence (applications servers, Web containers) which provide the components for a group of services appropriate for technological and social market trends, integration, selfmanagement, self-configuration, autonomy, independence from the platform hardware and software, flexibility, security, tolerance of faults and failures, enterprise continuity and ease of use.

The following elements are included in this process:

- Computational Industrial Machinery. This is the input element in the process and follows on from the physical normalisation process.

- Industrial Requirements. During the normalisation process the restrictions deriving from the industrial sector, real time, security, heterogeneity, physical limitations etc. should be taken into account

- Middleware Platform. The middleware of the industrial container is based on mature middleware platforms already existing in the market.

- eBusiness Architectures. The creation of middleware is controlled by the basic models and architectures which have had the most success in electronic business.

- Industrial Machinery as a Container. This is the result obtained from the process. An industrial machine with middleware infrastructures similar to service containers and software components.

\section{Services normalization}

The previous stages have enabled an industrial machine to become a service container on which business logic can be executed.

However, there is still a need to establish which services should be defined, how they should be organised together, how they relate to the physical components of the machine, and with the logic and services of other machines and manufacturing components or simply with the rest of the 
business processes. The elements involved in these phases (see figure 1.c) are:

- Industrial Machinery as a Container. This is the entry to the process to be transformed and the platform on which the service model of the industrial machinery will be based.

- Industrial Quality Requirements. These guarantee production quality and guide the modelling of services

- Service Oriented Architecture (SOA). Functional modelling of the industrial machinery is established on the basis of principles, paradigms and design patterns of the architectures oriented to services.

- Modelling Tools. These tools enable the modelling of services and components in the service normalisation process.

- Industrial Machine as a Service (IMaaS): These elements are the result of the transformation of industrial devices.

It is this phase of normalisation with the IMaaS concept in which the industrial machine is provided with the level of abstraction which will enable it to be presented to the rest of the organisation from the perspective of the functionality it is able to offer, facilitating integration of manufacturing processes within the organisation's general process map.

In order to achieve this goal, a service model has been defined to encapsulate all functionality of industrial machinery and the requirements introduced by the new production models. In this way, the services hide the technological characteristics features of the industrial machinery. In addition, the service model is based on organizational model largely used in the business process management in order to enable a direct integration with the global business process [21].

The service model has been divided into three sections according to the sector for which they are designed:

- Intrinsic services model of an industrial machine. (figure 2.c). This defines the services model, software components and their organisation in terms of an industrial machine however without yet taking into account which manufacturing processes will be involved in the future.

- Interaction model between machines. This defines the components and services required to compose new machinery or functionalities based on the cooperation, coordination or collaboration of a set of industrial equipment. Particularly in respect of the higher levels of the organisation this set of machinery will be seen as a sole piece of equipment with its specific functionalities and characteristics.

- Model of interaction with business processes. This defines the components and services required to
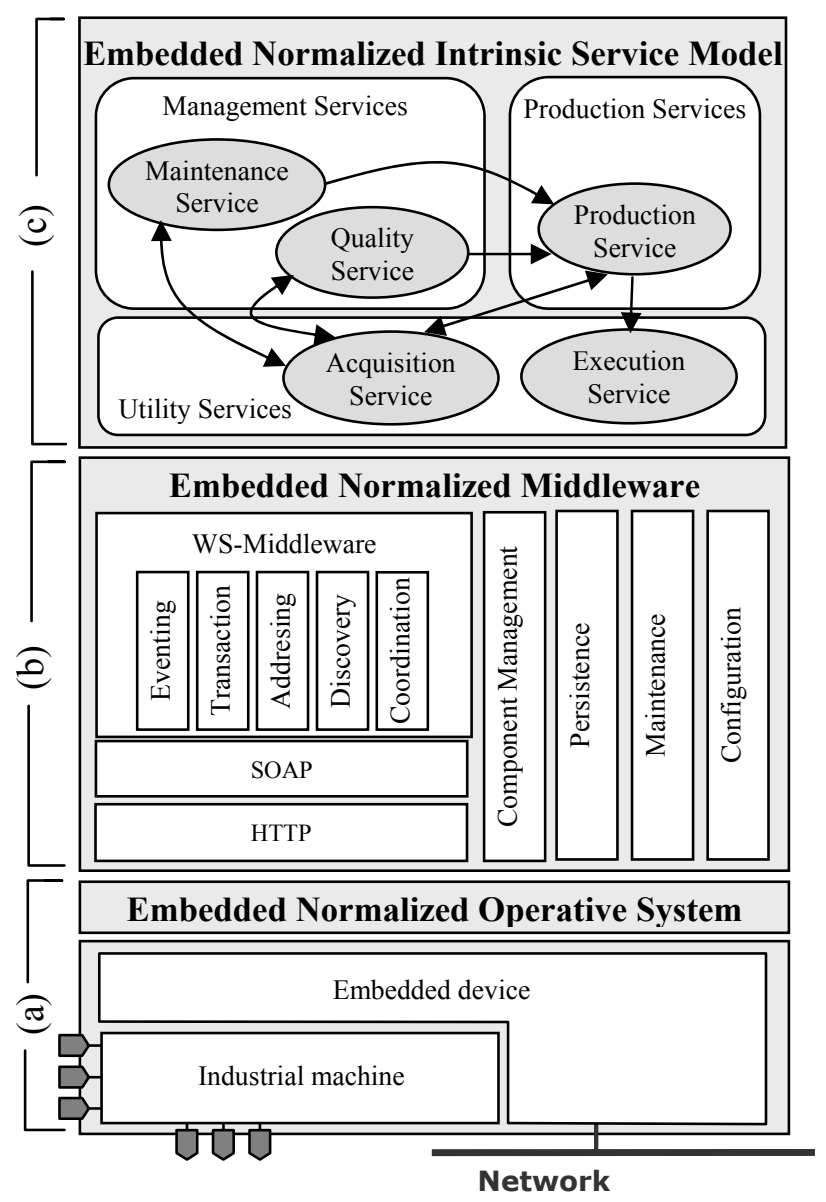

Figure 2. Software architecture of the normalized industrial machinery.

integrate an industrial machine in the global business process map in a transparent manner.

For reasons of space in this article we propose to concentrate on describing the intrinsic services modelling phase of an industrial machine.

\section{INDUSTRIAL MACHINE INTRINSIC SERVICES MODEL}

During this stage a model is obtained which defines the services, software components and their interrelation, which represent the performance and functionality of an industrial machine, regardless of the manufacturing processes in which it has to participate, and this functionality is guided by the requirements analysed in section II within new generation production models.

In this stage services offered by an industrial machine have been categorised, based on the general requirements of the manufacturing environments: supervision, control and the machine's actual process. This approach distinguishes three different types of services based on the behaviour of the services in the application layer of the manufacturing machinery: (a) production services, (b) management services and (c) utility services. 


\section{A. Production Services}

Production services (figure $2 \mathrm{c}$ ) are those which exhibit process logic or the functionalities of the industrial machinery. They establish a passive behaviour waiting requires from external components using paradigms concerned with services

Production services are based on an orchestration pattern with behaviour similar to that described in [11] and they act as intermediaries between management services and execution services when anomalies are detected in the process by the management services.

\section{B. Management Services}

In the proposed model types of management services have been defined on the basis of specific requirements of the industrial machinery. These requirements are management services (figure 2.c) and are proactive services which include the functionalities of control and supervision and they represent the process management of the industrial machinery. These components communicate autonomously with external control elements to send information in check the correct functioning of the manufacturing process - in this way added value is provided to the global business of the organisation (notification of errors in operation, reconfiguration of industrial machinery, maintenance controls etc)

Management services are based on the coordination pattern [22] in order to establish the work context and initiate the participants in the activity.

In the proposed model the types of management services have been defined on the basis of specific requirements.

These requirements are related to the improvements in the quality of the production process, of the industrial machinery: maintenance control of the industrial machinery mechanics and their components and quality control of the processes and products carried out in respect of that machinery.

B.1) The maintenance service represents local maintenance polices for an industrial machine. The aim is to achieve greater productivity and minimise risk of breakdown, thus improving production [15].

B.2) The quality service encapsulates the logic of quality control of the local process carried out by a machine and the resulting product in this phase. In order to measure the quality of factors, process and product, there is a need to establish a series of reference parameters which will reflect the objectives of the quality process.

\section{Utility Services}

Utility services (figure 2.c) provide functionality which is reused by other services in a general manner. In the proposed model the main utility services are: acquisition service and execution service

C.1) The acquisition service undertakes to acquire

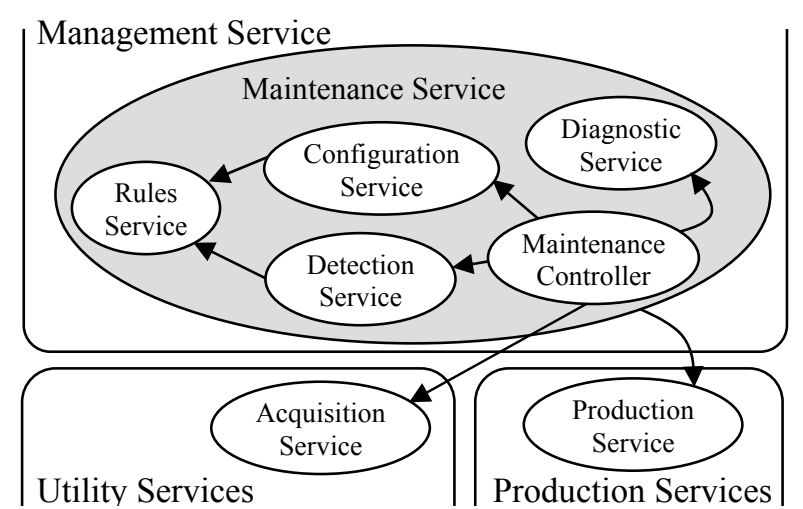

Figure 3. Maintenance service conceptual model.

information from sensors in the industrial machinery. This service can be parameterised on the basis of the context of the activity in which it is involved (maintenance, quality control, or production). The acquisition service is based on the orchestration [22] of the services encapsulating the functionality of the sensors.

C.2) The execution service exposes the functionality of the machine in terms of basic tasks of the mechanical components (control and management of actuators). It is a typical wrapper service [22] situated in the application layer of services.

\section{Maintenance Service Model}

From among the services described in figure 2.c we have chosen to focus our work on the description, composition and functioning of the maintenance service located in the management services(figure 3 ).

The object of the maintenance service is to encapsulate the maintenance management policies of an industrial machine. Specifically it established a predictive maintenance in order to detect faults before they occur, and correct them without detriment to the service or any halt in production. To achieve this the physical parameters associated with a mechanised system or an industrial machine are acquired through use of sensors (acquisition service of the service model) measured and registered in an immediate or continuous manner for the purpose of evaluating that information in order to take decisions on operability and maintenance of the machinery [16].

The maintenance service comprises the following services:

- The Controller Service orchestrates and directs the work flow of the maintenance activity: configuring the maintenance plan, obtaining sampling data, evaluating information, obtaining the procedure to be followed in the event of anomalies and launching the process.

- The Configuration Service undertakes to establish parameters for the maintenance activity. It 
encapsulates the rules of the behaviour of the industrial machine in entity-centric business services [22].

- The Detection Service detects maintenance anomalies based on regulations and models of normal behaviour of industrial machinery components according to the specific activity of the machine.

- The Diagnosis Service establishes the procedure to follow according to the anomaly detected.

- The Rules Service is a business service oriented towards the enterprise [22] and which encapsulates the parameter maintenance rules.

The maintenance service sustained by the coordination pattern establishes the creation of a coordination context with the requisite information for implementing the activity. This context in addition to maintenance i.e. performance variables to evaluate basic information from the pattern also includes information relating to the sensors that the performance variables to be assessed are required to provide, frequency of sampling etc.

\section{CONCLUSION}

This paper has proposed a method for modelling production machinery from the perspective of the services it is able to offer, based on ICT and SOA. By modelling machines in this way they are more easily incorporated in the global business model through production processes, integrating in a transparent manner in the organisation process map and avoiding discontinuities in procedures during execution of the business logic.

This article has focused almost exclusively on services intrinsic to an industrial machine in order to obtain a model which will define the services, software components and their interrelation, and which represents the behaviour and functionality of an industrial machine, regardless of the different manufacturing processes in which it may participate.

We are currently developing the remaining elements of the model, basically aspects relating to interaction with other industrial machinery or production elements, as well as integration at an enterprise level and at the level of business processes. As future lines of work it is proposed to incorporate semantics into the definition of services in order to facilitate self- confirmation, self- management and self-integration.

\section{REFERENCES}

[1] C. Younghwan, K. Kwangsoo, K. Cheolhan. "A design chain collaboration framework using reference models," International Journal of Advanced Manufacturing Technology. 26 (1) pp. 183-190. July, 2005.
[2] S.L.S. Worthington, W. Boyes. E-Business in Manufacturing: Putting the Internet to work in the industrial enterprise. ISA Press, 2002.

[3] V. Gilart-Iglesias, F. Maciá-Pérez, D. Marcos-Jorquera and F.J. Mora-Gimeno. "Normalization of industrial machinery with embedded devices and SOA". Proceedings of the 11th IEEE International Conference on Emerging Technologies and Factory Automation. Prague, 2006.

[4] P. Harmon, M. Rosen, M. Guttman. Developing E-business Systems and Architectures: A Manager's Guide. Morgan Kaufmann Publishers, San Francisco, USA. 2001.

[5] V. Gilart-Iglesias, F. Maciá-Pérez, J.M. García-Chamizo, A. Hernández-Sáez, D. Marcos-Jorquera. "A model for developing J2EE applications based on design patterns," Proceedings of IADIS International Conferences on Applied Computing, IADIS-AC'05. IADIS Press, 2005.

[6] R.P. Moreno. Ingeniería de la automatización industrial. Ra-Ma, Madrid, Spain, 2004.

[7] Transparent Factory. Manual de usuario y planificación. [Online] Available: http://www.modicon.com, 2001.

[8] U. Topp, P. Müller. "Web based service for embedded devices," International Workshop on Web Service: Research, Standardization and Deployment (WS-RSD'02). Lecture notes in computer science. Web, Web Service and Database Systems, pp. 141-153, 2002.

[9] A.P. Kalogeras, J.V. Gialelis, C.E. Alexakos, M.J. Georgoudakis, S.A. Koubias. "Vertical integration of enterprise industrial systems utilizing Web Service," Proceedings of the 5th IEEE International Workshop on Factory Communication System (WFCS 2004), Technical University of Vienna, Vienna, Austria, 22-24 September 2004.

[10] F. Jammes, H. Smit. "Service-Oriented paradigms in industrial automation," IEEE Transaction on industrial informatics. VOL I. $\mathrm{n}^{\circ}$ 1, pp. 62-70. 2005.

[11] F. Jammes, H. Smit, J.L. Martinez-Lastra, I.M. Delamer. "Orchestration of Service-Oriented Manufacturing Processes," Proc. of the 10th IEEE International Conference on Emerging Technologies and Factory Automation, ETFA 2005, Catania, Italy, September 19-22, 2005

[12] V. Gilart-Iglesias, F. Maciá-Pérez, J.A. Gil-Martínez-Abarca and A. Capella-D'alton. "Industrial Machines as a Service: A model based on embedded devices and Web Services". Proceedings of 4th International IEEE Conference on Industrial Informatics (INDIN'06). Singapore, 2006.

[13] S-M. Lee et al. "A component-based distributed control system for assembly automation". Proceedings of 2 nd International Conference on Industrial Informatics. INDIN 2004.

[14] D.C. McFarlane and S. Bussmann. "Developments in Holonic Production Planning and Control." Intenational Journal of Production Planning and Control, Vol. 11, No. 6, pp. 522 -- 536, 2000.

[15] M.C. Carnero. "An evaluation system of the setting up of predictive maintenance programmes". Reliability Engineering and System Safety, vol.91, pp.945-963, 2005.

[16] M.C. García-Fernández et al. "Aplicación de técnicas de inteligencia artificial en el mantenimiento predictivo de aerogeneradores". Proceddings of IV Jornadas de Fiabilidad: Confiabilidad. 2002.

[17] C. A. Cianfrani and J.E. West. ISO 9001:2000 aplicada a la fabricación. AENOR. 2004.

[18] F. Gómez-Fraile et al. Como hacer el manual de calidad según la nueva ISO 9001:2000. Fundación Confemetal. 2005.

[19] J. Catsoulis. Designing embedded hardware. Second edition. O'Reilly, USA, 2005.

[20] D. Gill, J. Hobday. Internet embedded devices for industrial applications. ERA Technology, UK. 1999.

[21] P. Harmon. Business Process Change. A manager's guide to improving, redesigning and automating processes. Morgan Kaufmann Publishers, San Francisco, USA. 2003.

[22] T. Erl. Service-Oriented Architecture.Concepts, technologies and design. Prentice Hall. 2005. 